\title{
Oxidation of Propane-1,3-diol (Non-Vicinal) by Potassium Permanganate in Aqueous Medium, A Kinetic Study
}

\section{Dayo Felix Latona}

Department of Pure and Applied Chemistry, Osun State University, PMB 4494 Osogbo, Nigeria

\section{A R T I C L E I N F O}

Received: 27 July 2019

Revised: 07 August 2019

Accepted: 13 September 2019

Available online: 27 September 2019

\section{K E Y W O R D S}

Potassium permanganate

Propane-1,3-Diol

Kinetics

Mechanism

\section{A B S T R A C T}

The oxidation of propane-1,3-diol by potassium permanganate in aqueous solution was investigated at $\lambda_{\max } 525 \mathrm{~nm}$. The rate of the reaction was found to increase with increase in $\left[\mathrm{KMnO}_{4}\right]$ and [Propane-1,3-diol]. The reaction showed first order dependence each in [ $\left.\mathrm{KMnO}_{4}\right]$ and [Propane-1,3-diol] and independent on the ionic strength of the solution. The activation parameters were evaluated from Arrhenius and Erying's equations and the values of $\llbracket \Delta \mathrm{H} \rrbracket$ ${ }^{\wedge} \#\left(\mathrm{~kJ}\right.$ mol-1), $\llbracket \Delta \mathrm{S} \rrbracket^{\wedge} \#(\mathrm{kJK}-1 \mathrm{~mol}-1)$ and $\llbracket \Delta \mathrm{G} \rrbracket{ }^{\wedge} \#(\mathrm{kJmol}-1)$ were $24.98,-0.22$ and 90.50 respectively. Negative entropy of activation revealed an association mechanism and an ordered transition state for the reaction. Stoichiometric study showed 1:1 consumption of $\mathrm{KMnO}_{4}$ and propane-1,3-diol. Spectroscopic studies and FTIR analysis revealed the product of the reaction to be 3-hydroxyl-propanal. A suitable reaction mechanism was proposed for the reaction investigated.

GRA P H I C A L A B S TRACT

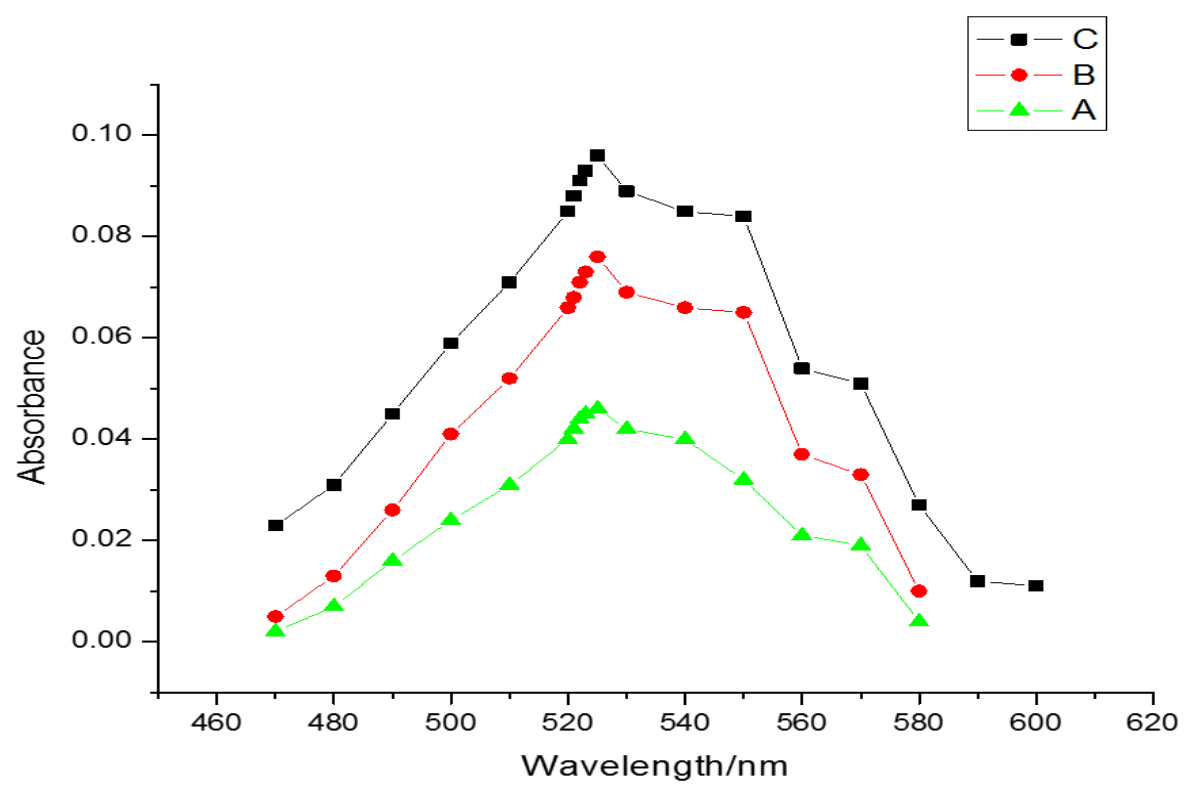

* Corresponding author's E-mail address: dayo.latona@uniosun.edu.ng 


\section{Introduction}

Potassium permanganate discovered by Margueritte in 1846 has now been widely used for redox reactions involving a variety of chemical reactions. It is a versatile strong oxidizing agent in both acidic and alkaline media which has been employed for the oxidation of various organic compounds like alcohols [1-3], aldehydes and ketones [4-6], amines [7], glyoxal and glyoxalic acid [8]. There are few reports in the literature on the oxidation of Diols. However, oxidants like tetrabutylammonium tribromid e(TBATB) [9], cerium (IV) $[10,11]$, benzyltrimethylammonium tribromi e [12], 12-tungstocobaltate (III) anion [13], trialkylammonium fluorochromates (VI) [14], tripropylammonium fluorochromate [15], barium manganite [16] have been employed for the oxidation of diols. Oxidation of diols by MN (VII) has not been reported in the literature. Therefore, this research is aimed at investigating the kinetics and mechanism of the oxidation of propane-1,3diol by a strong oxidant like $\mathrm{KMnO}_{4}$.

\section{Experimental}

\section{Materials and methods}

Potassium permanganate (AR), Propane1,3-diol (BDH), Potassium nitrate (AR), Ferrous ammonium sulphate (AR) and sulphuric acid (BDH) were used without further purification by preparing their stock solutions in doubly distilled water. Potassium permanganate was standardized using Ferrous ammonium sulphate in acidic medium. The kinetic study was done using 1800 UVShimadzu Spectrophotometer with a thermostated cell compartment and interfaced with a computer. Freshly prepared solutions were used in all the kinetic studies. The ionic strength of the solution was kept constant with potassium nitrate.
Kinetic study

The oxidation reaction was studied under pseudo-first order kinetics by keeping concentrations of propane-1,3-diol in excess of potassium permanganate concentrations at 298 K. Appropriate quantities of the reaction mixtures of propane-1,3-diol and potassium nitrate were measured into the cuvette. Consequently, the reaction was initiated by adding requisite volume of $\mathrm{KMnO}_{4}$ solution. All stock solutions were kept in a water bath for 30 minutes before the kinetic runs and progress of the reaction was followed by monitoring decrease in absorbance of $\mathrm{KMnO}_{4}$ as a function of time at $\lambda_{\max } 525 \mathrm{~nm}$. The pseudo-first order rate constant ( $\mathrm{k}_{\mathrm{obs}}$ ) were obtained from a plot of In A versus time.

\section{Stoichiometry}

The stoichiometry was accomplished by spectroscopic titration at $525 \mathrm{~nm}$. The absorbance at infinite time of reaction mixtures containing different initial concentrations of propane-1,3-diol within the range $2.66 \times 10^{-3}-1.07 \times 10^{-2} \mathrm{M}$ at fixed $\left[\mathrm{KMnO}_{4}\right]$ and ionic strength at $3.97 \times 10^{-5}$ and $6.67 \times 10^{-3} \mathrm{M}$ respectively were obtained. Consequently, the stoichiometry of the reaction was determined from the plot of Absorbance at infinite time versus concentration of propane-1,3-diol. The stoichiometry was found to be one mole of $\mathrm{KMnO}_{4}$ per one mole propane-1,3-diol.

\section{Product analysis}

A solution of 2 drops of the product in $2 \mathrm{ml}$ of $95 \%$ ethanol was added to $3 \mathrm{~mL}$ of 2,4dinitrophenylhydrazine reagent. Formation of a precipitate confirms the presence of carbonyl compound [17].

\section{Induced polymerization of acrylamide}

The oxidation of the vicinal diols by $\mathrm{KMnO}_{4}$, in nitrogen atmosphere did not induce polymerization of acrylamide. Indicating 
absence of free radicals in the course of the reaction.

Effect of potassium permanganate concentration

The effect of $\mathrm{KMnO}_{4}$ was studied with the view to ascertaining the order of reaction with respect to $\left[\mathrm{KMnO}_{4}\right]$. This was done by varying $\left[\mathrm{KMnO}_{4}\right]$ within the range 9.37x $10^{-6} \mathrm{M} \leq[\mathrm{KMnO} 4] \leq 6.67 \times 10^{-5} \mathrm{M}$ at fixed [Propane-1,3-diol] and ionic strength at $4.00 \times 10^{-3} \mathrm{M}$ and $6.67 \times 10^{-3} \mathrm{M}$ respectively.

\section{Effect of propane-1,3-diol concentration}

The effect of [Propane-1,3-diol] on the oxidation reaction was carried out in order to obtain the order of reaction with respect to the [diol] and also to ascertain the second order rate constant of the reaction. More so, to confirm whether the oxidation reaction followed Michaelis-Menten kinetics. The effect of propane-1,3-diol concentration on the reaction was studied by varying [Propane-1,3diol] within the range $1.34 \times 10^{-3} \mathrm{M} \leq$ [Propane1,3-diol $] \leq 1.07 \times 10^{-2} \mathrm{M}$ and fixing $\left[\mathrm{KMnO}_{4}\right]$ and ionic strength at $3.97 \times 10^{-5} \mathrm{M}$ and $6.67 \times 10^{-3} \mathrm{M}$ respectively.

\section{Effect of Ionic strength}

The effect of ionic strength was determined in order to determine the ions present at the rate determining step. This was carried out by varying the ionic strength of the reaction solution within the range $1.33 \times 10^{-3} \mathrm{M} \leq \mu \leq$ $1.33 \times 10^{-2} \mathrm{M}$ and keeping concentrations of $\mathrm{KMnO}_{4}$ and propane-1,3-diol constant at 3.97x $10^{-5} \mathrm{M}$ and $4.00 \times 10^{-3} \mathrm{M}$ respectively at $298 \mathrm{~K}$.

\section{Effect of Temperature}

Activation parameters were determined from temperature dependent study by fixing [KMnO 4 ] [Propane-1,3-diol] and ionic strength, $\mu$ at $3.97 \times 10^{-5} \mathrm{M}, 4.00 \times 10^{-3} \mathrm{M}$ and $6.67 \times 10^{-3} \mathrm{M}$ respectively and varying temperature of the reaction mixtures within $298 \mathrm{~K} \leq \mathrm{T} \leq 318 \mathrm{~K}$. Activation parameters were obtained from the below equations [18].

$$
\begin{gathered}
\log k=\log A-\frac{E_{a}}{2.303 R T} \\
\ln \left(\frac{k}{T}\right)=\frac{-\Delta H^{\ddagger}}{R T}+\ln \left(\frac{k^{\prime}}{h}\right)+\left(\frac{\Delta S^{\ddagger}}{R}\right) \\
\ln \left(\frac{k^{\prime}}{h}\right)=23.76 \\
\Delta \mathrm{G}^{\#}=\Delta \mathrm{H}^{\#}-\mathrm{T} \Delta \mathrm{S}^{\#}
\end{gathered}
$$

Where $\mathrm{k}$ is the observed rate constant, $\mathrm{T}$ is Temperature in Kelvin, $\Delta H^{\#}$ is Enthalpy of activation, $\Delta \mathrm{S}^{\#}$ is Entropy of activation, $\Delta \mathrm{G}^{\#}$ is Free Gibb's energy of activation, $\mathrm{R}$ is the Molar gas constant, $\mathrm{k} /$ is Boltzmann's constant and $\mathrm{h}$ is the Planck's constant.

\section{Reaction orders}

Pseudo-first order rate constant ( $\left.\mathrm{k}_{\mathrm{obs}}\right)$ increased with increase in the concentration of $\mathrm{KMnO}_{4}$ (Figure 1). The order is unity with respect to $\left[\mathrm{KMnO}_{4}\right]$. Increase in pseudo-firstorder rate constant $\left(\mathrm{k}_{\text {obs }}\right)$ with increase in diol concentration was observed (Table 1) and the slope of in $\mathrm{k}_{\mathrm{obs}}$ versus In [Propane1,3-diol] gave 1, indicating a first order dependence with respect to diol concentration.

Second order rate constant obtained from the slope of the plot of $\mathrm{k}_{\mathrm{obs}}$ versus [Propane-1, 3diol] was $4.87 \times 10^{-2} \mathrm{M}^{-1} \mathrm{~s}^{-1}$. Variation of ionic strength of the reaction mixture using $\mathrm{KNO}_{3}$ did not affect the rate of reaction, implying the presence of a neutral molecule at the rate determining step. There was a considerable increase in the pseudo-first order rate constant ( $\mathrm{k}_{\mathrm{obs}}$ ) with increase in temperature (Figure 2) and activation parameters in Table 2 were obtained from Arrhenius and Erying's equations. 
Figure 1. Effect of $\left[\mathrm{KMnO}_{4}\right]$

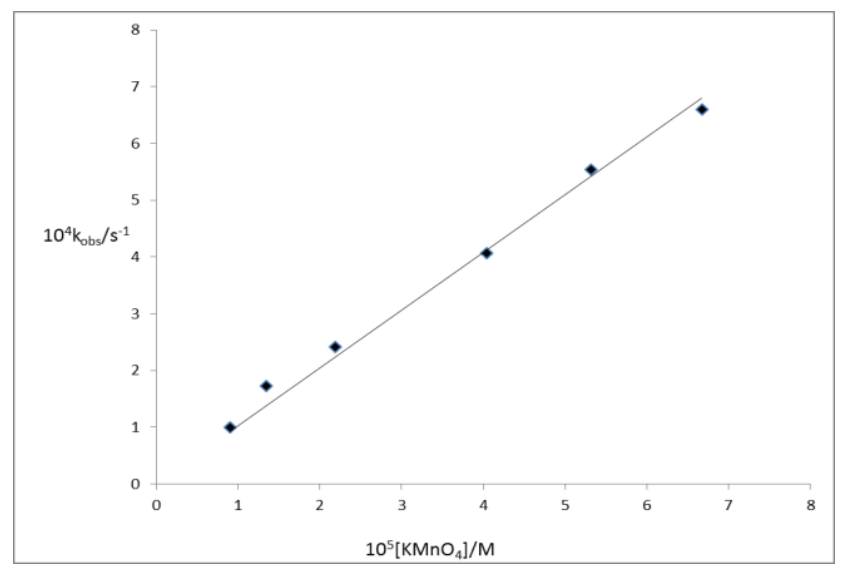

Table 1. Effect of [Diol]

\begin{tabular}{cc}
$10^{3}[$ Diol $] / \mathrm{M}$ & $10^{4} \mathrm{k}_{\mathrm{obs}} / \mathrm{s}^{-1}$ \\
2.66 & 1.67 \\
4.00 & 2.30 \\
5.34 & 2.82 \\
6.67 & 3.56 \\
8.00 & 3.86 \\
9.34 & 4.42 \\
10.70 & 4.83 \\
\hline
\end{tabular}

Figure 2. Effect of temperature

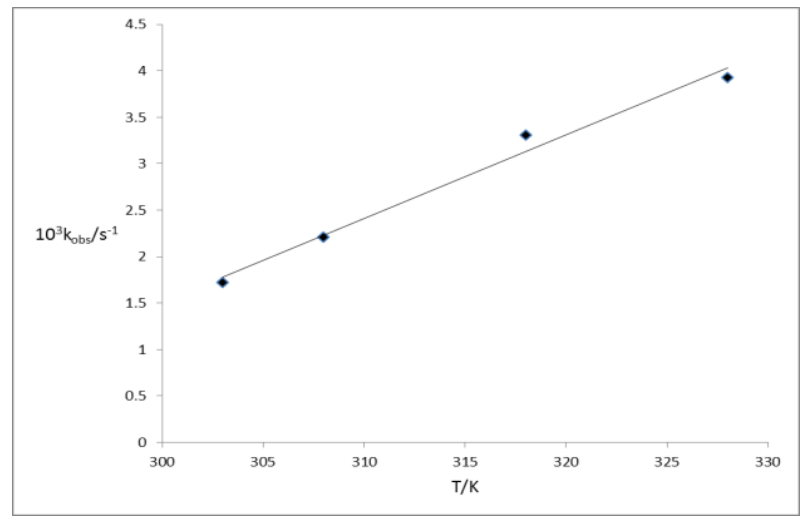

Table 2. Activation parameters

\begin{tabular}{ccccc} 
Diol & Ea $\left(\mathrm{kJ} \mathrm{mol}^{-1}\right)$ & $\Delta H^{\#}(\mathrm{~kJ} \mathrm{~mol}-1)$ & $\Delta S^{\#}\left(\mathrm{kJK}^{-1} \mathrm{~mol}^{-1}\right)$ & $\Delta G^{\#}\left(\mathrm{~kJ} \mathrm{~mol}^{-1}\right)$ \\
Propane-1,3-diol & 27.53 & 24.94 & -0.22 & 90.50 \\
\hline
\end{tabular}

\section{Spectral Studies}

The spectral of $\mathrm{KMnO}_{4}$ and $\mathrm{KMnO}_{4}+$ Propane-1,3-diol at three different concentrations of diol indicated an increase in the absorbance of $\mathrm{KMnO}_{4}$ as the concentration of diol increases (Figure 4). However, the absorbance of the reaction mixture decreased with time. This revealed the formation of an intermediate pre-equilibrium complex which led to product formation [4]. 
Figure 3. Michaelis-Menten plot
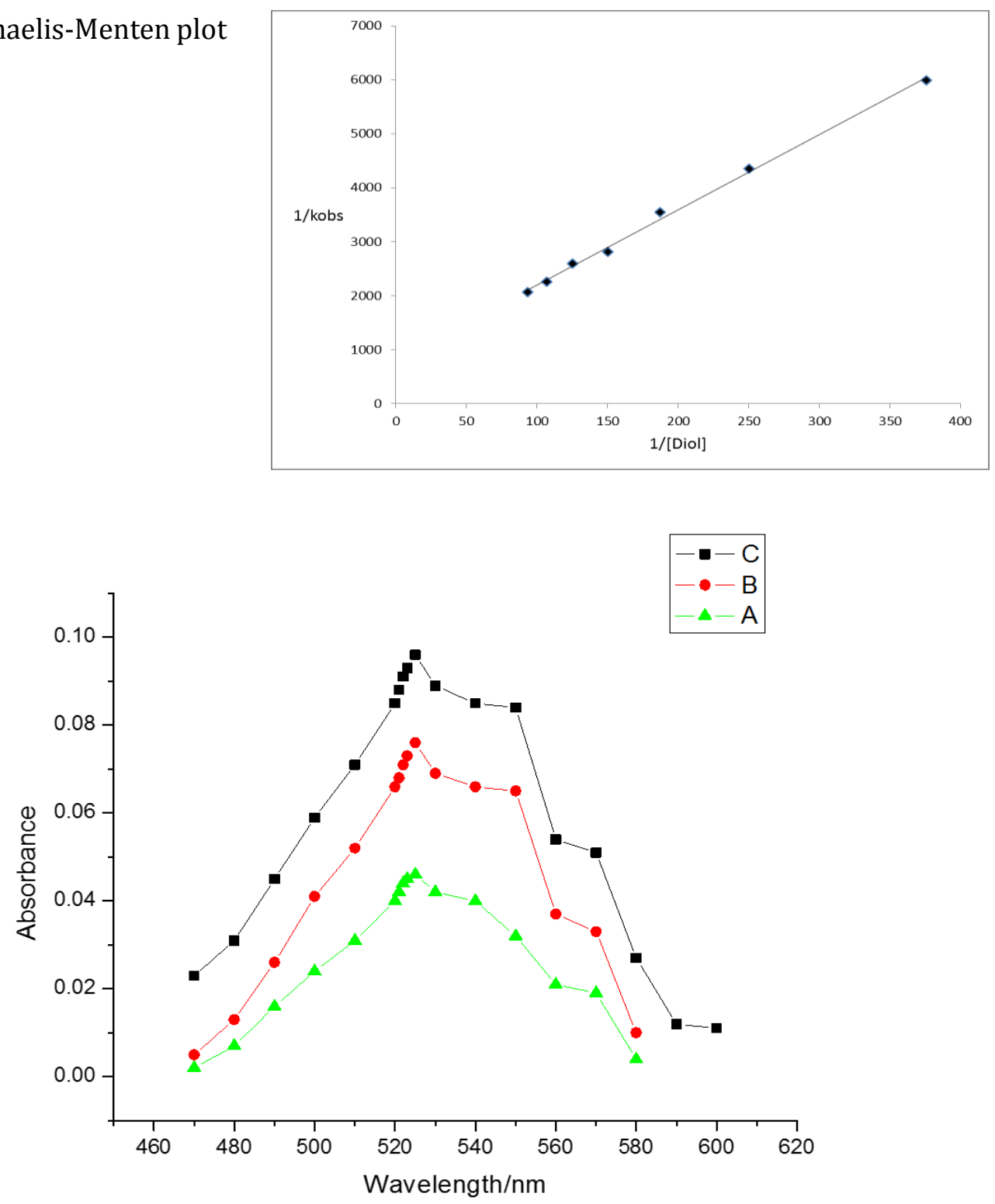

Figure 4. UV-VIS spectra of [A] $3.97 \times 10-5 \mathrm{~mol} / \mathrm{dm}-3 \mathrm{KMnO}+1.34 \times 10-3 \mathrm{~mol} / \mathrm{dm}-3 \mathrm{Diol}+$ $6.67 \times 10-3 \mathrm{KNO} 3 \mathrm{~mol} / \mathrm{dm}-3,[\mathrm{~B}] 3.97 \times 10-5 \mathrm{~mol} / \mathrm{dm}-3 \mathrm{KMnO} 4+5.34 \times 10-3 \mathrm{~mol} / \mathrm{dm}-3 \mathrm{Diol}+$ $6.67 \times 10-3 \mathrm{KNO} 3 \mathrm{~mol} / \mathrm{dm}-3,[\mathrm{C}] 3.97 \times 10-5 \mathrm{~mol} / \mathrm{dm}-3 \mathrm{KMnO} 4+8.00 \times 103 \mathrm{~mol} / \mathrm{dm}-3 \mathrm{Diol}+$ $6.67 \times 10-3 \mathrm{KNO} 3 \mathrm{~mol} / \mathrm{dm}-3$

Rate law

Michaelis-Menten plot of $1 / \mathrm{k}_{\mathrm{obs}}$ versus $1 /$ [Diol] gave a straight line graph with an intercept, indicating the presence of an intermediate complex (Figure 3). The kinetic study showed first order dependence on each of $\left[\mathrm{KMnO}_{4}\right]$ and [Diols].

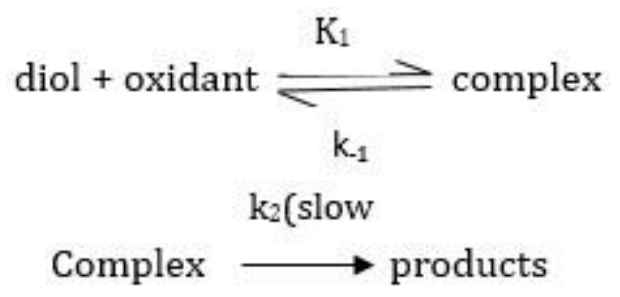

Applying steady state approximation:

$$
\text { Rate }=\mathrm{k} \text { [diol] [oxidant] }
$$

Where, $\mathrm{k}=\frac{k_{2} k_{1}}{k_{-1}+k_{2}}$ 


\section{Mechanism of Reaction}

The use of quinolinium dichromate for the oxidation of non-vicinal diols yielded $\alpha$ hyroxy carbonyl compounds with a mechanistic pathway involving the intermediate formation of a chromate ester, which undergoes decomposition to yield the product [18]. FTIR spectrum analysis of product showed no observable oxidation of the second hydroxyl group in the diol. The FTIR spectrum showed $\mathrm{O}-\mathrm{H}$ broad peak at $3200-3500 \mathrm{~cm}^{-1}$ and $\mathrm{C}=0$ stretching at 1725 $\mathrm{cm}^{-1} \mathrm{C}$-H stretching of weak band at about $2850 \mathrm{~cm}^{-1}$ of aldehydes. A hydrogen abstraction mechanism of one-electron oxidation leading to the formation of free radicals is ruled out due to lack of polymerization with acrylamide [19]. The overall mechanism is proposed to involve the formation of a manganate ester in a fast preequilibrium step and then a decomposition of the ester to product as shown in Scheme 1 . When an anion reacts with a neutral molecule to form an intermediate complex as in this case, the charge is dispersed over large area in the product. Hence the charge density is reduced and the complex formation is enhanced by decrease in the water content of the solvent mixture [12]. Negative value of $\Delta S^{\#}$ indicates an association mechanism and a rigid transition complex [20].
Figure 5. FTIR-Spectrum of the product

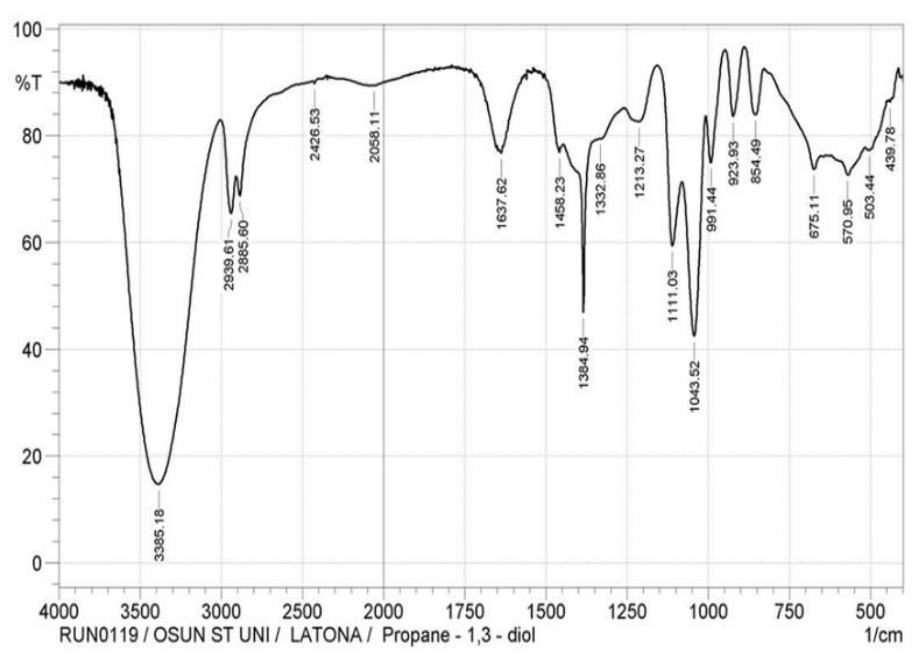

Scheme 1. The proposed mechanism of 3-hydroxylpropanal formation
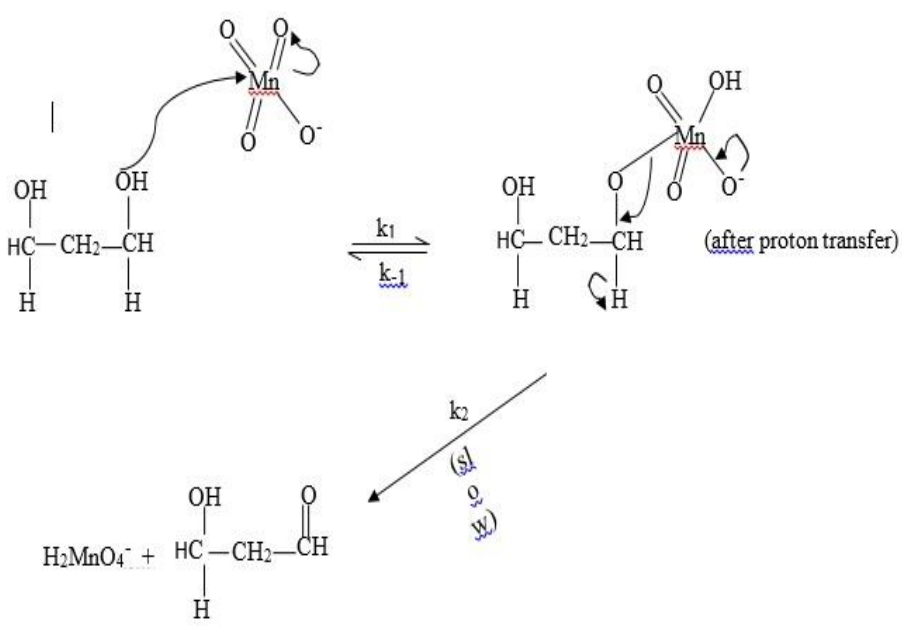


\section{Conclusion}

The reaction is first order each to $\left[\mathrm{KMnO}_{4}\right]$ and [Propane-1,3-diol]. The product of the reaction is 3-hydroxyl-propanal and the stoichiometric study suggests 1 mole consumption of propane-1,3-diol by 1 mole of $\mathrm{KMnO}_{4}$.

\section{Disclosure statement}

No potential conflict of interest was reported by the author.

\section{Acknowledgement}

The author acknowledges the financial support by the Osun State University, Osogbo and the technical staff in the central science laboratory of the Obafemi Awolowo University, Ile-Ife for the use of their state of the art laboratory.

\section{References}

[1] D.G. Lee, T. Chen, J. Org. Chem., 1991, 56, 5341-5345.

[2] K.K. Sen Gupt, M. Adhikari, S. Sen Gupta, React. Kinet. Catal. Lett., 1989, 38, 313-318.

[3] S.I. Montalvo, J.D. Ingle, Talanta, 1993, 40, 167-172.

[4] M. Jaky, J. Szammer, J. Phys. Org. Chem., 1997, 10, 420-426.

[5] L. Zhu, L. Song, W. Chen, Y. Gao, C. Zhang, J. Wang, J. Qian, Russian J. Appl. Chem., 2017, 90, 1326-1329.
[6] P. S. Rao, Z. Phys. Chem, 1974, 255, 382384.

[7] H. Schechter, S.S. Rawalay, J. Am. Chem. Soc., 1984, 86, 1706-1709.

[8] W.L. Evans, H. Adkins, J. Am. Chem. Soc., 1919, 41, 1385-1414

[9] J. Gosain, P.K. Sharma, J. Chem. Sci., 2003, 115, 135-145.

[10] P.K. Tandon, S. Khanam, S.C. Yadav, R.C. Shukla, Transit. Metal Chem., 2011, 36, 739-746.

[11] P.K. Tandon, S.Z. Khanam, S.B. Singh, Open Catal. J., 2012, 5, 1-7.

[12] G. Goswami, S. Kothari, K.K. Banerji, J. Chem. Sci., 2001, 113, 43-54.

[13] M.A. Olatunji, G.A. Ayoko, Bulletin de la societe chimique de France, No 5, 1985, pp. 705-708.

[14] S. Ghammany, S. Khorsandtabar, A. Moghimi, H. Sahebalzamani, J. Mex. Chem. Soc., 2009, 53, 41-43.

[15] S.S. Mansoor, S.S. Shafi, Arabian J. Chem., 2016, 9, S602-S609.

[16] S.C. Pati, B.R. Dev, R.C. Mahapatro, Proc. Ind. Nant. Sci. Acad., 1981, 47, 335-344.

[17] W.J. Svirbely, A.K. Kundell, J. Am. Chem. Soc., 1967, 89, 5354-5359.

[18] B. Kuotsu, E. Tiewsoh, A. Debroy, M.K. Mahanti, J. Org. Chem., 1996, 61, 88758877.

[19] S. Saraswat, V. Sharma, K.K. Banerji, J. Chem. Sci., 2003, 115, 75-82.

[20] J.E., Huheey, R. EAK, Keiter. Inorganic Chemistry: Principles of Structure \& Reactivity $4^{\text {th }}$ Ed., 1993, 547-576.

How to cite this manuscript: Dayo Felix Latona, Oxidation of Propane-1,3-diol (NonVicinal) by Potassium Permanganate in Aqueous Medium. A Kinetic Study, Adv. J. Chem. A, 2020, 3(3), 343-349. 